\title{
Vitamin D and seasonal variation among Greek female patients with osteoporosis
}

G. Papadakis (1), I. Keramidas (1), K. Kakava(2), T. Pappa(1), V. Villiotou(3),

P. Manitarou(1), S. Kalaitzidou(1), E. Triantafillou(1), V. Kaltzidou(1), A. Pappas(1)

Departments of 'Endocrinology, ${ }^{2}$ Otolaryngology and ${ }^{3}$ Biochemical Department, Anticancer Hospital of Piraeus "Metaxa"

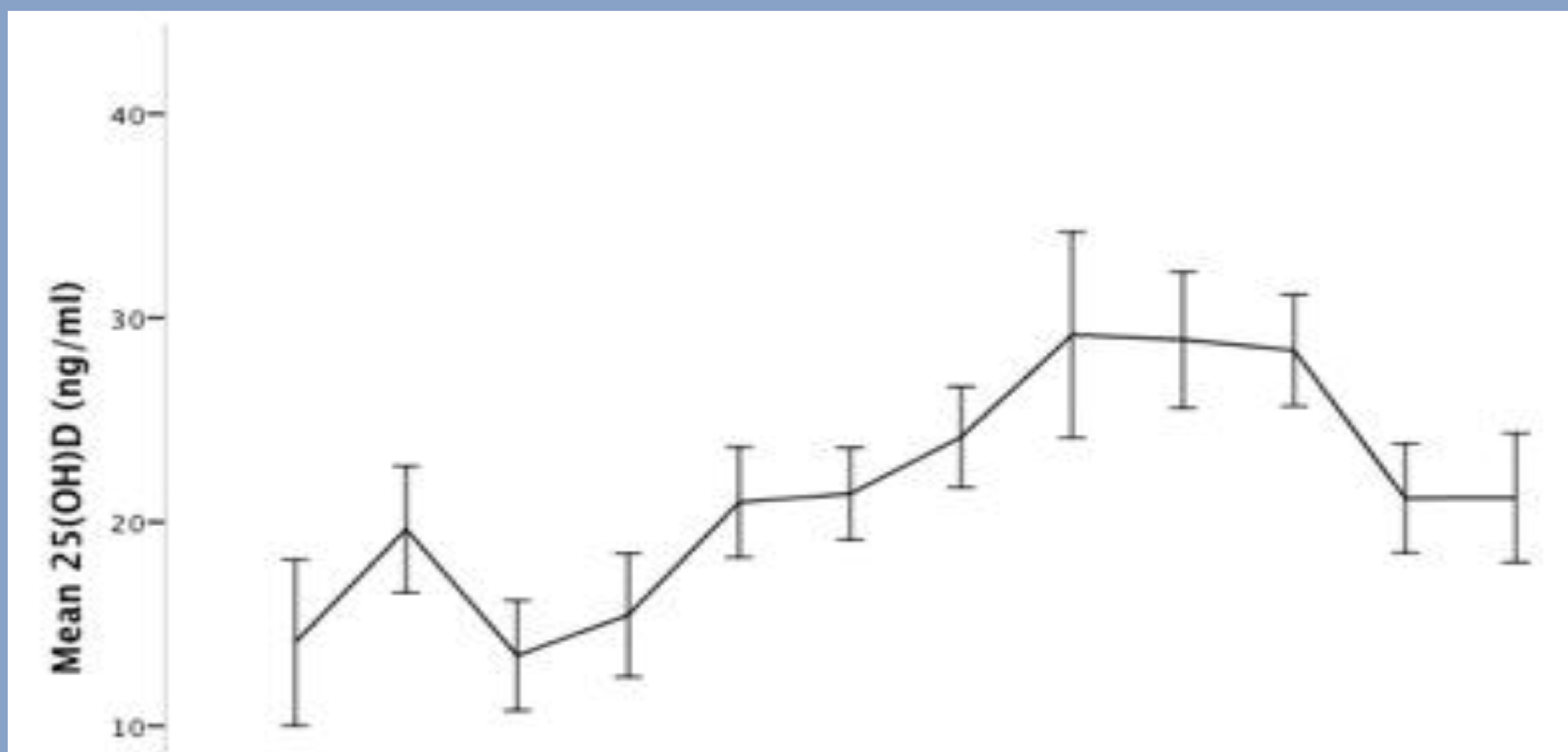

Background: 25 hydroxy vitamin D [25(OH)D] vitamin levels are positively associated with bone mineral density and season, time of day and sun exposure duration influence its synthesis. Variations in daylight throughout the year and zenith angle, depending on the latitude of residence, influence ultraviolet solar radiation which is closely related to serum 25(OH)D levels. The aim of this study was to investigate the degree of seasonal variation of $25(\mathrm{OH}) \mathrm{D}$ serum levels in a population-based cohort of postmenopausal women with osteoporosis. Methods: Serum levels of 25(OH)D were assessed in 596 Greek patients [mean age 65.3 years old; standard deviation $(S D)=9.4]$ in different months between August 2012 and December 2014. Each patient contributed one blood sample during the observation period and all women received vitamin $D$ supplements as a multivitamin tablet or as a Calcium carbonate with vitamin $D$ chewable tablet. Total hip bone mineral density was measured by dualenergy X-ray absorptiometry and all women had a T-score of -2.5 or less. Results: The minimum 25(OH)D serum level was observed in March $(13.4 \pm 9.5 \mathrm{ng} / \mathrm{ml})$ and the maximum levels in August, September and October $(29.1 \pm 16.1 ; 28.9 \pm 12$ and $28.4 \pm 8,9 \mathrm{ng} / \mathrm{ml}$ respectively). The prevalence of vitamin deficiency $(<20 \mathrm{ng} / \mathrm{ml})$, insufficiency $(20-<30$ $\mathrm{ng} / \mathrm{ml}$ ) and sufficiency ( $\geq 30 \mathrm{ng} / \mathrm{ml}$ ) in March was $76.5,15.7$ and $7.8 \%$ respectively. On the contrary, the highest prevalence of vitamin D sufficiency was observed in August, September and October $138.1 \% ; 45.3 \%$ and $46.5 \%$ respectively). Conclusion: Seasonal variations should be considered when measuring and correcting vitamin $D$ serum levels. Although Greece is a country with sunshine, the majority of postmenopausal women with osteoporosis do not reach sufficient $25(\mathrm{OH}) \mathrm{D}$ levels, regardless of type and dose of vitamin D supplementation and degree of sun exposure.

Figure 1. Monthly mean levels of 25(OH) D in $\mathrm{ng} / \mathrm{ml}$.

$\mathrm{Cl}$, confidence interval; $25(\mathrm{OH}) \mathrm{D}, 25$ hydroxy vitamin $\mathrm{D}$.

Figure 2. Monthly prevalence of 25(OH)D status (deficiency, insufficiency and sufficiency) 